\title{
ORCA Has Lost One of Its Pioneers
}

On the 13th of November 2020, our long-standing Swiss member Prof. Dr. Thomas Marthaler passed away at the age of 91 years. From very early on, Tomi Marthaler, as many friends called him, took an international and scientific approach to dentistry. He spent the year after his graduation in the USA. Back in Switzerland, he combined working in the family practice with scientific work at the University of Zurich. Like many other pioneers in cariology, he was driven by the question of how to prevent the enormous burden of dental caries in many highly developed countries, instead of treating the damage caries caused. Switzerland was definitely a prime place for this in the 1950s, when ORCA was also founded.

Very systematically, Prof. Marthaler found partners in the Swiss School Dental Services, developed a sound epidemiological base, and analyzed the influence of dietary factors in the process of caries which was not fully understood at that time. The big breakthrough occurred when many researchers concentrated on the caries-preventive effect of fluorides, which was one of the founding topics of ORCA. Thomas Marthaler examined the properties of amine fluorides and played an important role in establishing their regular application in Swiss schools. This very simple but systematic approach led to an incredible decline in caries of over $90 \%$ and was an outstanding success for caries research with its epidemiologic, basic science, and community dentistry branches. Thomas Marthaler thus set an example for young researchers and caries prevention in many other countries. Modern caries preven-

karger@karger.com

(c) 2021 S. Karger AG, Basel

www.karger.com/cre

Karger

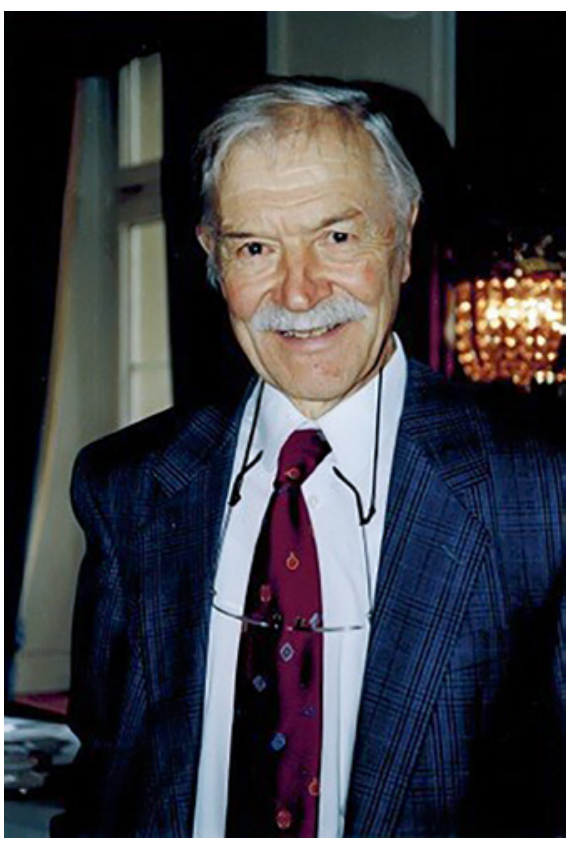

Prof. Dr. Thomas Marthaler

tion improved the quality of life of whole populations and countries and Thomas Marthaler helped to make this possible. ORCA acknowledged these achievements by awarding him the Junior Rolex Prize in 1966. He was part of the international ORCA family, presenting their current research at annual conferences and enriching the evening event with a group of very vocal entertainers. 
In Switzerland, his outstanding achievements were rewarded with an "Außerordentliche Professur", an "extraordinary" Professorship for Oral Epidemiology and Preventive Dentistry at the University of Zurich. He formed a network with colleagues such as Hans Mühlemann, Klaus König (who was actually called his preventive twin brother), and Klaus Rateitschak, and Zurich became one of the leading centers for preventive and biologically based dentistry, both in cariology and periodontology. They developed the idea and regulations for labeling sweets as "tooth-friendly," a logo used in many countries.

Prof. Marthaler was also involved in spreading the idea of fluoridated salt as a population-wide preventive ap- proach. Very quickly, his endeavors became a benchmark for other activities for caries prevention, he initiated an international comparison of the caries decline published in Caries Research, and he also served as adviser to the WHO and US CDC. In appreciation of his contributions, he became an Honorary Member of ORCA after his retirement.

ORCA has lost a true member and a role model for scientific and humanitarian engagement in cariology. Our hearts are with his family and friends.

Christian Splieth, on behalf of the ORCA board and the whole ORCA family 